dans le petit-lait limpide, exempt de ces cellules et de lactacidase, l'acidité était restée presque telle qu'elle était au moment de la séparation de cette partie limpide du liquide originel.

De cette expérience, on peut conclure que :

$1^{0}$ Par l'acidification prolongée du petit-lait, provoquée par la fonction du Bacterium lactis acidi, on peut obtenir un liquide qui contient plus de $1 \%$ d'acide lactique ;

$2^{\circ}$ Cette acidification élevée est en partie causée par la fonction biochimique des cellules vivantes, mais surtout par la "lactacidase» des cellules détruites.

\title{
NOTES SUR LA FABRICATION DU YOGHOURT AU TCHAD (1)
}

\author{
par \\ JACQUES ALLARD.
}

Les essais effectués sur des laits indigènes de cette région (Fort-Lamy) ont donné les résultats qui vont faire l'objet de cette étude.

Deux tubes à essais de lait stérilisé furent ensemencés le 3 août 1931, respectivement de "bacille bulgare " et de "paralactique ", puis furent fermés à la flamme et expédiés liquides par colis postal, via la Nigeria anglaise, à Fort-Lamy.

Les tubes de ferments arrivèrent à destination vers le 25 septembre, coagulés régulièrement, bien que la température favorable de culture $\left(40\right.$ à $45^{\circ}$ C.) n'ait pas été atteinte pendant le voyage. Dès leur arrivée, l'expérimentateur bénévole commenęa ses essais de fabrication, d'abord pour sa consommation personnelle. Il prit un litre propre, et le stérilisa par ébullition sur un bain-marie et selon les moyens de fortune dont il disposait, il recueillit proprement le lait de la traite et malgré les difficultés matérielles de bien stériliser les récipients, le fit bouillir.

A $45^{\circ}$ C., température favorable de culture des ferments, le litre de lait étant resté soigneusement bouché, l'opérateur brisa les deux tubes et versa leur contenu dans la bouteille, agita celle-ci et la boucha, puis, après s'être assuré que la température ambiante resterait constante pendant 8 à 10 heures, il déposa la bouteille à la température atmosphérique, qui est, à cette époque de l'année, comprise entre $+30^{\circ}$ et $+35^{\circ}$, à l'abri des rayons solaires.

(1) Les renseignements locaux et les échantillons ont été fournis par M. Georges DELUz, ingénieur agricole, commis des Services civils, à Fort-Iamy. 
Le levain ainsi coagulé régulièrement, servit de base de fermentation.

Malheureusement, la température favorable de culture ne put être rigoureusement maintenue vers $40^{\circ}$, faute d'étuve et de thermomètre précis ; celle-ci tomba plus souvent à la température ambiante de $35^{\circ}$. Les pots furent recouverts de linge selon la méthode turque et le produit obtenu présenta bien, à la dégustation, les qualités requises du yoghourt. Il est à noter que, par suite d'une pratique fort rudimentaire et avec un matériel défectueux, l'arome et l'acidité du caillé disparaissaient assez vite; néanmoins les cultures sur du lait donnèrent de meilleurs résultats que les ferments en poudre, "genre maya bulgare ", utilisés sur place.

Dans cette région de brousse équatoriale, les soins donnés au lait sont médiocres, étant donné la chaleur et le manque total de force électrique et de matériel frigorifique (les sels frigorigènes qui ont été essayés se prennent en masse pendant le voyage). La fabrication du beurre y est donc assez difficile. L'eau est refroidie simplement par évaporation, en plaçant des "gargoulettes" (sortes de cruches en terre) autant que possible dans un fort courant d'air.

Le bétail laitier est composé surtout de bovins en assez grande quantité, par rapport au reste de l'A. E. F., où sévit la mouche "tsé-tsé". La vache laitière de la région de Fort-Lamy n'est aucunement sélectionnée; elle fournit en moyenne 4 à 5 litres de lait par jour, et voici les résultats del'analyse d'un échantillon expédié le 15 octobre 1931 et reçu à Paris le 19 décembre (via le Cameroun).

Les résultats de l'analyse chimique et de l'examen bactériologique furent les suivants :

\section{Examen physico-chimique.}

\begin{tabular}{|c|c|}
\hline 150 & \\
\hline é à $15^{\circ} \ldots \ldots \ldots \ldots \ldots \ldots \ldots \ldots \ldots \ldots \ldots \ldots$ & $1.031,5$ \\
\hline sec total $\ldots \ldots \ldots \ldots \ldots \ldots \ldots \ldots$ & 128 gr. 49 \\
\hline sec dégraissé $\ldots \ldots \ldots \ldots \ldots \ldots \ldots$ & 90 gr. 49 \\
\hline rasse $\ldots \ldots \ldots \ldots \ldots \ldots \ldots \ldots \ldots \ldots$ & 38 gr. \\
\hline ides totaux. . . . . . . . . . . . . . . . & 24 gr. 05 \\
\hline$\ldots \ldots \ldots \ldots \ldots \ldots \ldots \ldots \ldots \ldots \ldots \ldots \ldots \ldots \ldots$ & 57 gr. 49 \\
\hline$\ldots \ldots \ldots \ldots \ldots \ldots \ldots \ldots \ldots \ldots$ & 8 gr. 95 \\
\hline Cendres insolubles $\ldots . \ldots \ldots \ldots \ldots \ldots \ldots \ldots \ldots$ & $5 \mathrm{gr} .30$ \\
\hline solubles & 3 gr. 65 \\
\hline alorures (exprimés en $\mathrm{NaCl}), \ldots \ldots \ldots \ldots \ldots \ldots$ & 1 gr. 225 \\
\hline
\end{tabular}

Constantes calculées.

Constan te moléculaire simplifiée apparente du sérum $\ldots \ldots . \quad 72,06$

Constante moléculaire réelle du sérum $\ldots \ldots \ldots \ldots \ldots \ldots \quad \mathbf{7 6 , 7 4}$ 


\section{Examen bactériologique.}

L'ensemencement aseptique sur tubes de lait stérile ont donné une première coagulation à $+35^{\circ}$, après 3 jours d'étuve seulement, arec une acidité de $229^{\circ}$ D., puis une seconde coagulation sur tubes de lait stérile à $+40^{\circ}$, après 11 jours d'étuve, avec une acidité de $160^{\circ} \mathrm{D}$.

Après 4 jours d'étuve à $40^{\circ}$, poussa seul un bâtonnet thermophile, long et filiforme, prenant le Gram, après ensemencements directs sur lait et tous milieux gélosés.

Après 10 jours, sur gélose, poussèrent des colonies rondes et blanches (levures du lactose = saccharomyces acidi lactici) et des colonies roses (du genre torula) ainsi que de très petites colonies blanches communes (du genre Micr. acidi lactis).

\section{CONCLUSIONS.}

Il ressort de la composition chimique de ces laits une grande richesse en lactose, propice aux fermentations acidifiantes, aux ferments du yoghourt et du képhyr, équilibrée par une faible quantité de chlorures (constante moléculaire normale et prouvant une forte concentration du sérum). La quantité de caséine ( $24 \mathrm{gr} .05$ par litre) est faible, tandis que celle des cendres ( 8 gr. 95) est assez élevée.

La densité, les matières grasses et l'extrait total sont ceux d'un lait normal.

Les microorganismes qui ont été isolés sont presque tous thermophiles, travaillant surtout sur le lactose, acidifiant fortement le milieu.

De tels laits se prêtent donc favorablement à la fabrication du yoghourt ou du képhyr, selon les méthodes originales.

\section{NOUVELLE THÉORIE CONCERNANT L'ACTION DE LA PRÉSURE SUR LA CASÉINE DU LAIT (1)}

\section{par}

\section{MaUrice BEAU \\ Ingénieur agronome.}

\section{THEORIE GHIMIQUE DU DÉDOUBLEMENT.}

C'est au chimiste suédois 0 . Hammarsten que l'on doit à la fois les premiers travaux d'ensemble et la première théorie en ce qui

(1) Lo présent article est la synthèse des idées exposées par l'auteur dans deux notes précédentes : la première, intitulée « Sur la coagulation du lait par la présure ", présentée le $1^{\text {er }}$ octobre 1931 au XIe Congrès de Chimie industrielle à Paris (voir comptes rendus de ce congrès dans le numéro spécial de Chimie et Industrie de mars 1932); la seconde, intitulée - Comment la présure agit sur la caséine du lait », parue dans le Volume jubilaire en l'hon. neur du Professeur Ch. Porcher, en avril 1932. 